\title{
Stirling Isotope Power Systems for Stationary and Mobile Lunar Applications
}

\author{
Paul C. Schmitz ${ }^{\mathrm{i}}$ \\ Power Computing Solutions, Inc., Avon, OH 44011 \\ L. Barry Penswick ${ }^{\mathrm{ii}}$ \\ Sest, Inc., Middleburg Heights, OH 44130 \\ Richard K. Shaltens ${ }^{\text {iii }}$ \\ NASA Glenn Research Center, Cleveland, OH 44135
}

The NASA Exploration Systems Architecture Study (ESAS) places a significant emphasis on the development of a wide range of capabilities on the lunar surface as a stepping-stone to further space exploration. An important aspect of developing these capabilities will be the availability of reliable, efficient, and low-mass power systems to support both stationary and mobile applications. One candidate system to provide electrical power is made by coupling the General Purpose Heat Source (GPHS) with a high-performance Stirling convertor. In this paper we explore the practical power range of GPHS/Stirling convertor systems all with conductively coupled hot-end designs for use on the lunar surface. Design and off-design operations during the life of the convertor are studied in addition to considering these varying conditions on system. Unique issues concerning Stirling convertor configurations, integration of the GPHS with the Stirling convertor, controller operation, waste heat rejection, and thermal protection are explored. Of particular importance in the evaluation process is a thorough understanding of the interactions between the wide range of unique lunar environments and the selection of key systems operating characteristics and the power systems design. Additionally, as power levels rise the interface between the GPHS and Stirling and the Stirling and the radiator begins to dominate system mass and material selection becomes more important. 


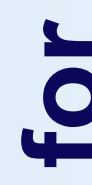

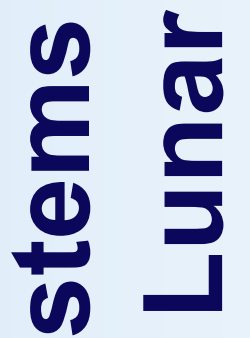

$\infty \omega$

느을

(1) 0

$\geq \pm$

0 。

(1)

운 운

○

(s)

ㅇ) 훙

E

$=\infty$

는

吾

$\boldsymbol{\infty}$

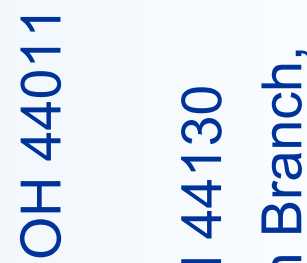

ㄷำ

\& $\quad \stackrel{\infty}{=} \frac{1}{\Phi}$

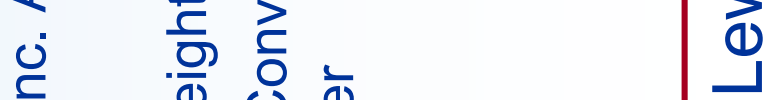

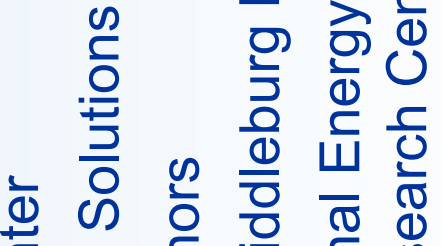

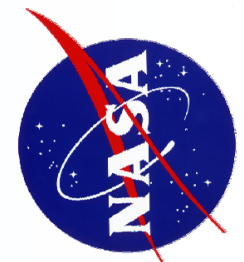

$\frac{\overline{0}}{0}$
$\frac{1}{4}$
$\frac{0}{3}$
$\frac{1}{0}$
$\frac{1}{\sigma}$

ก

을 至 ह

凹

है

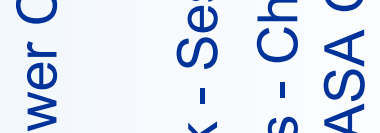

¿

i. $\quad \sum_{0}^{\frac{1}{\pi}}$

苋 $\quad \frac{c}{0}$

ज

ن 

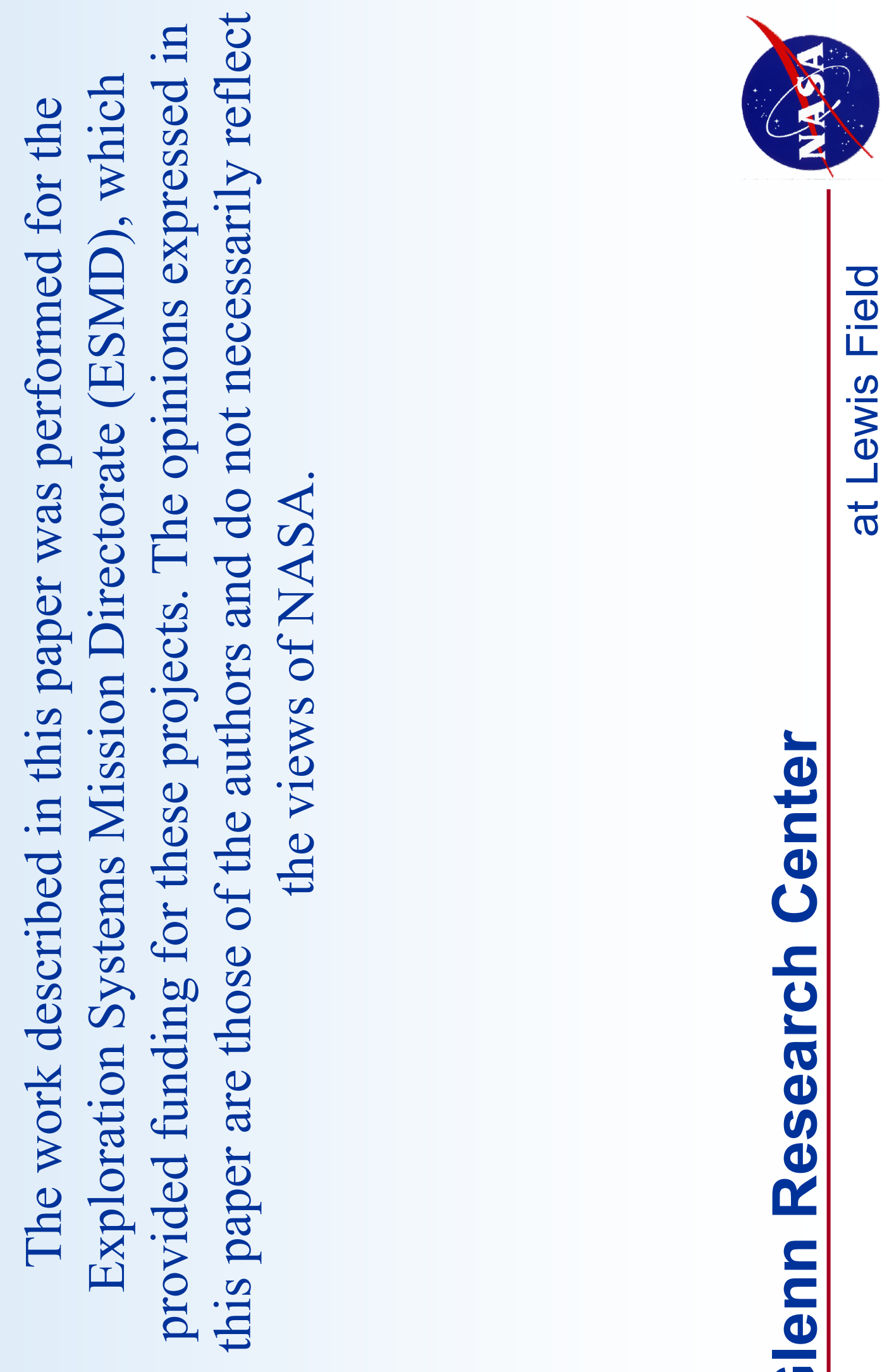

$\frac{}{i \frac{1}{4}}$

$\frac{-\infty}{3}$

ฮั)

논

$\frac{E}{\sigma}$ 
18 는

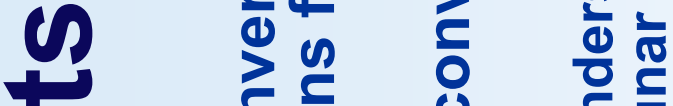

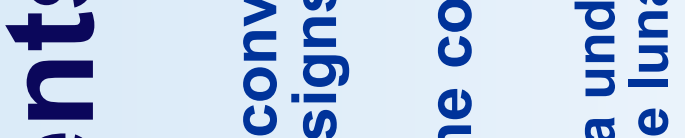

(1) 0)

E 든 0 으을

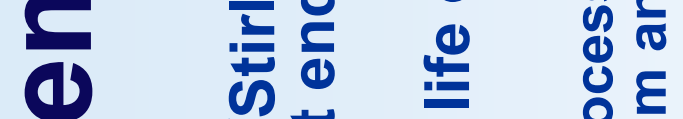

(1) के क

- 드 트 은

ए 으 응

(1) 1 응 항

(1) 0 응 0 은

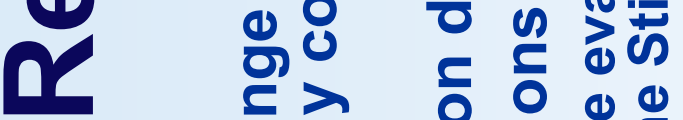

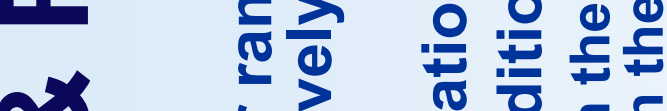

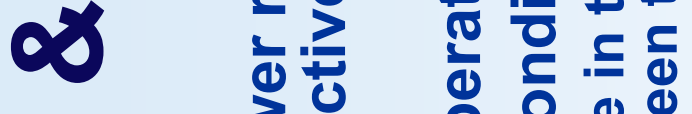

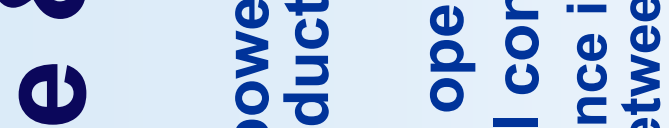

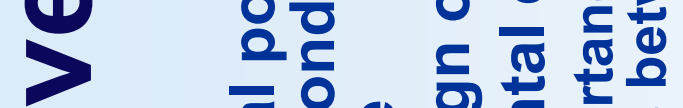

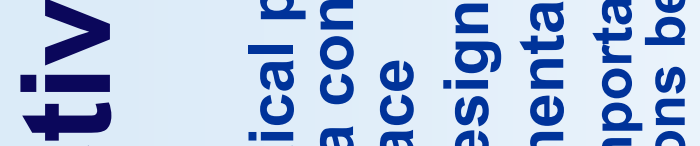

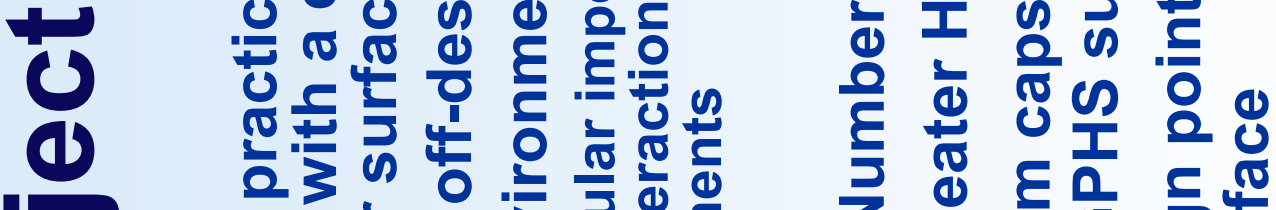

(1)

(1)

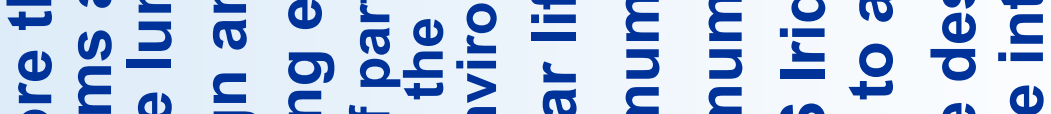

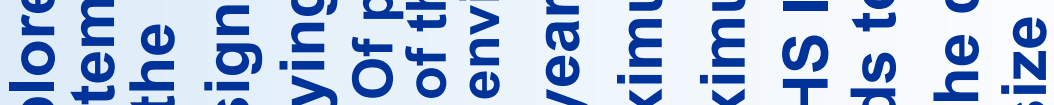

읍

U内

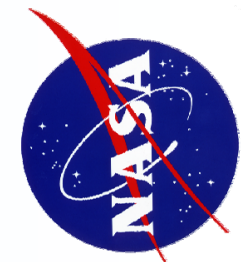

$\frac{0}{0}$
$\frac{1}{4}$
$\frac{3}{3}$
$\frac{1}{\pi}$

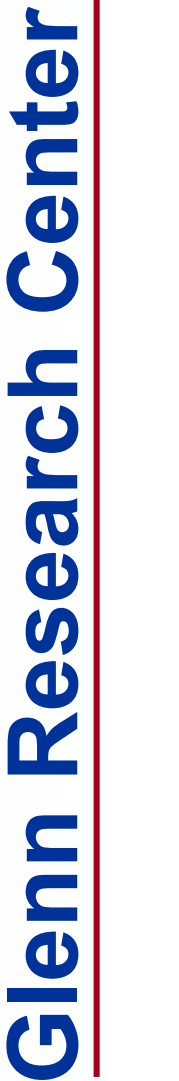




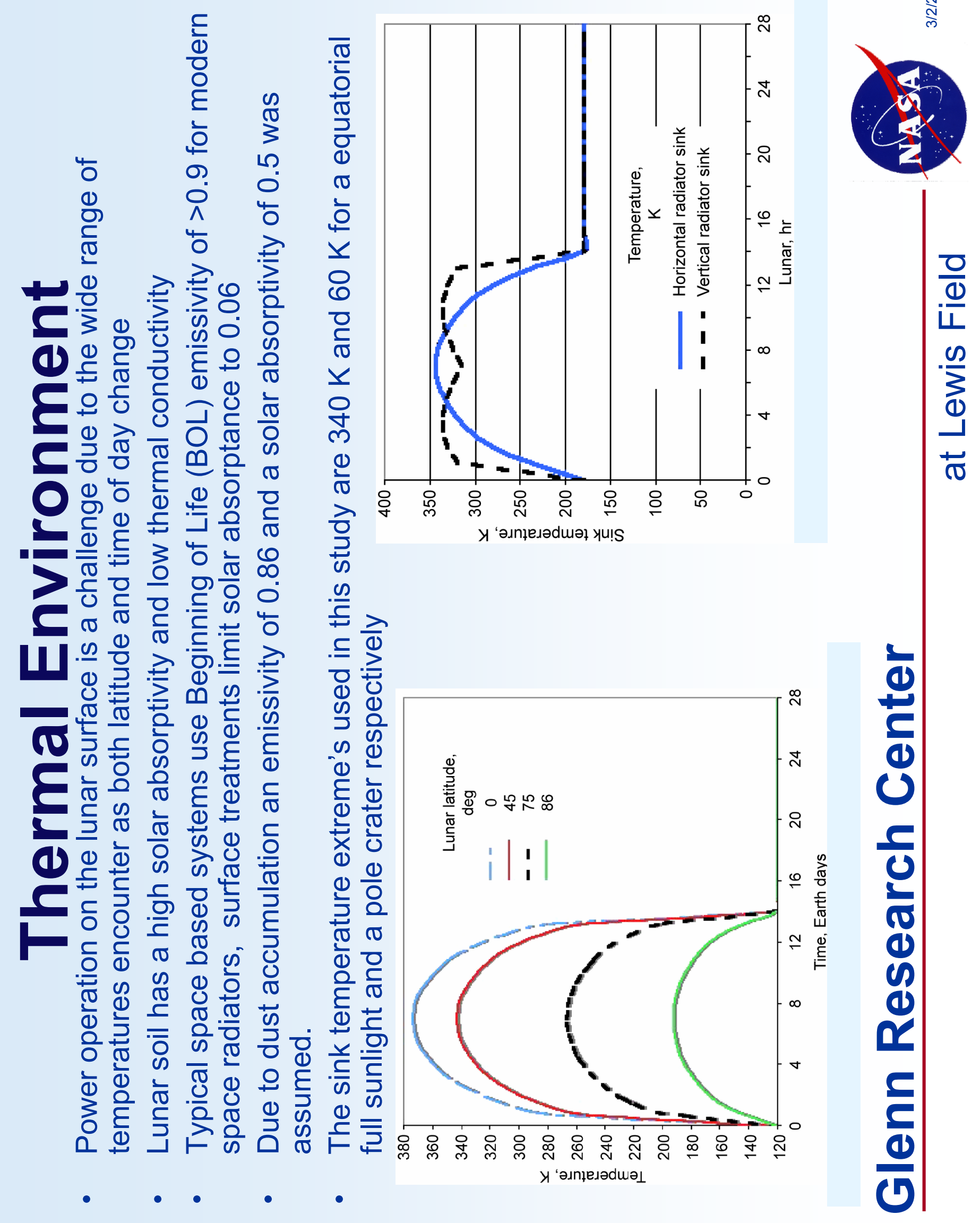




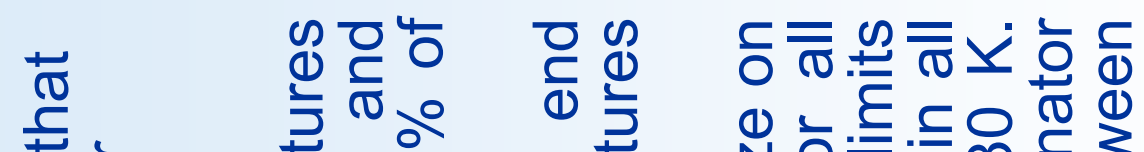

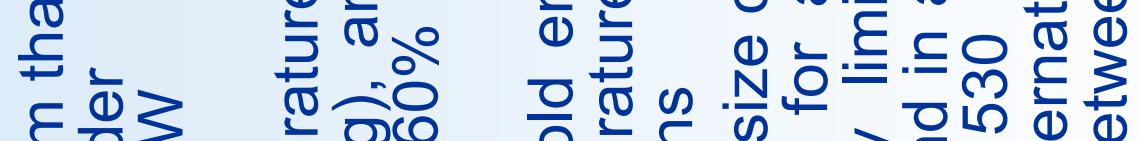

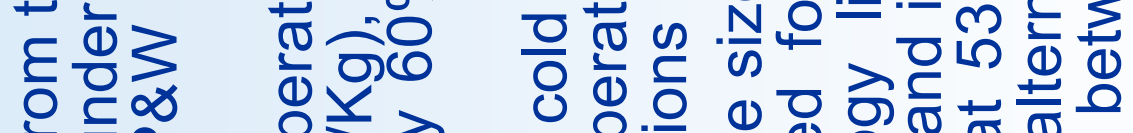
는

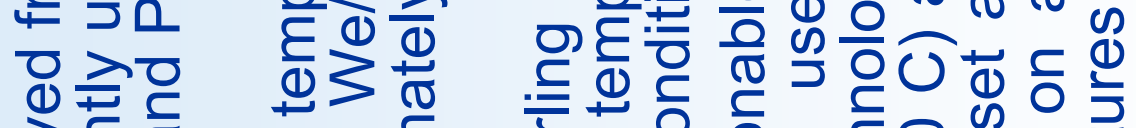
\衣的 ब1 0 ర亏

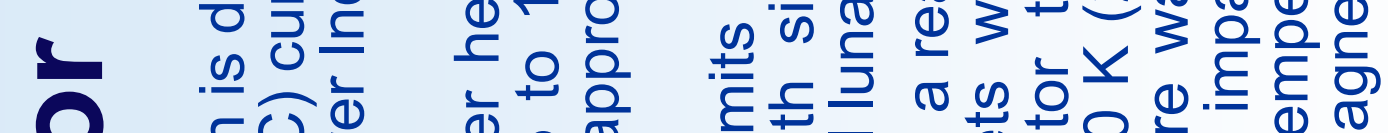
ᄃิ๊ + . 응

(1) 전을 $\mathbb{\infty} \underbrace{4}$ >

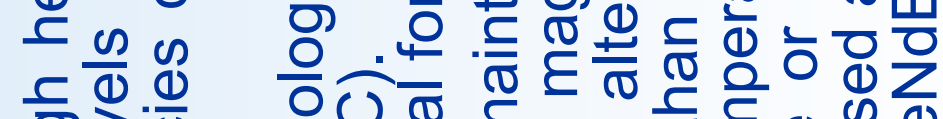

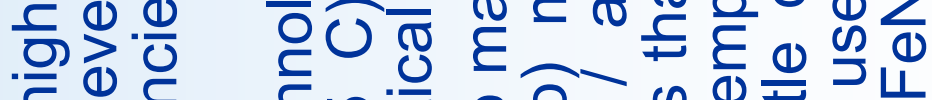
(1)

을 응 등 $\frac{1}{d} \cdot \frac{1}{0}$

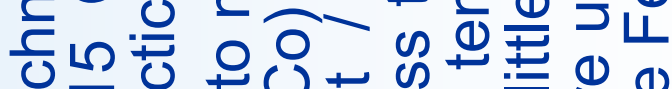

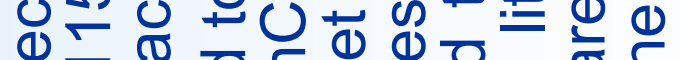

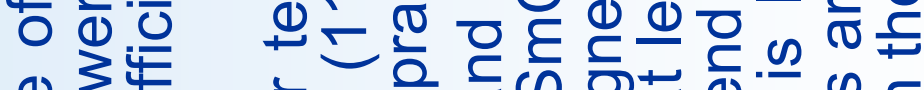

$(1) \cong$

की 0

(2) 은

이느믕

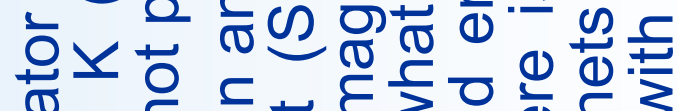

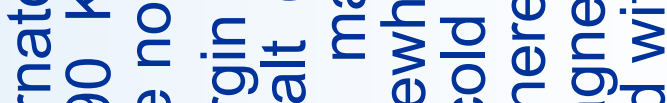
동요 윰 잉

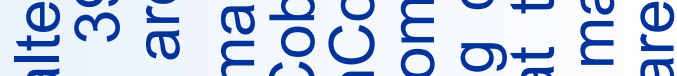

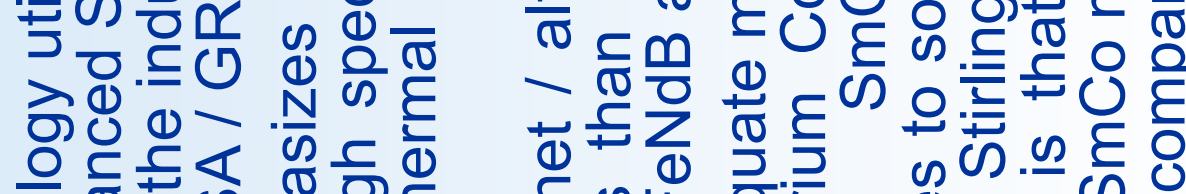

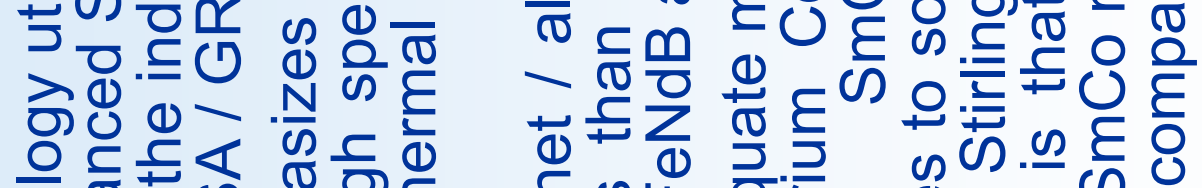

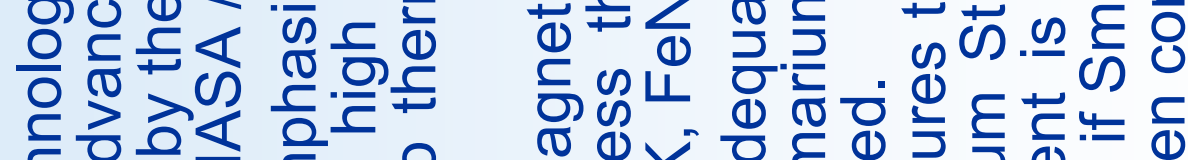

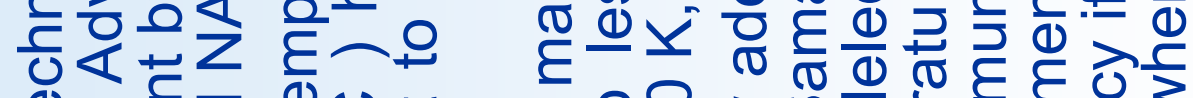

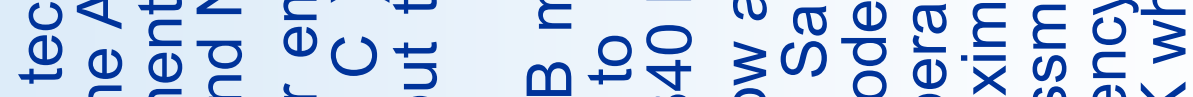

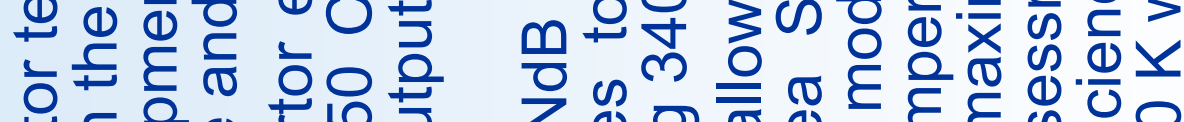

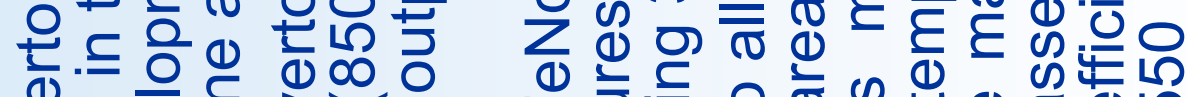

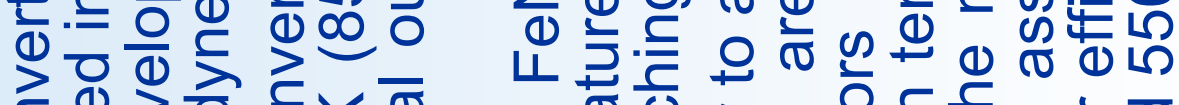

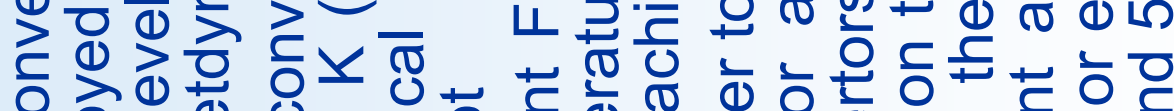

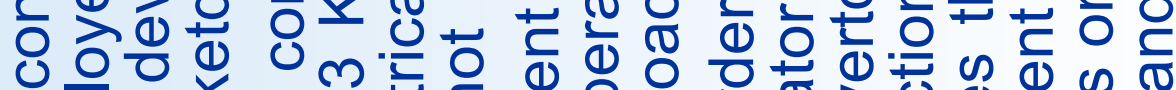
U응 승

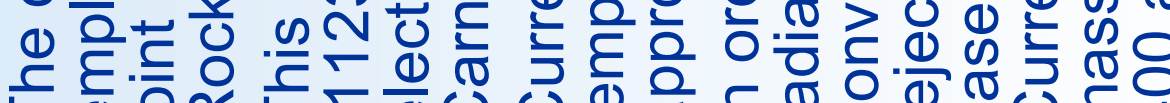
등.으 

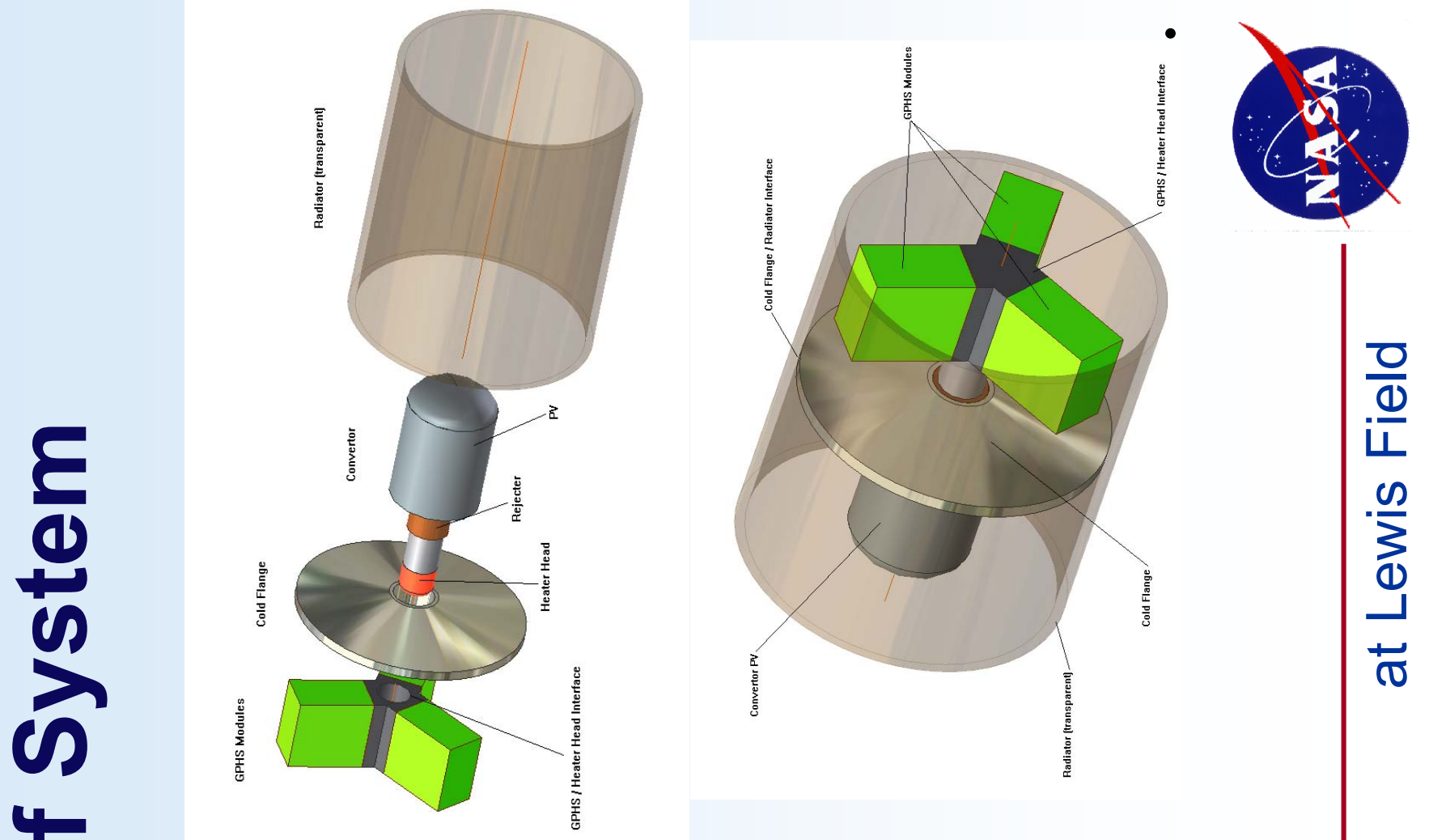

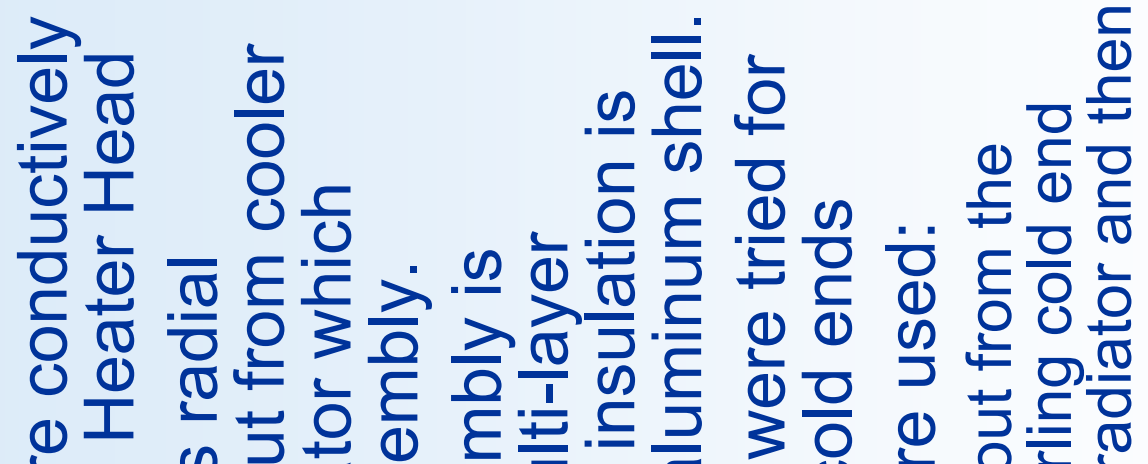

市

ஸे 흔듀

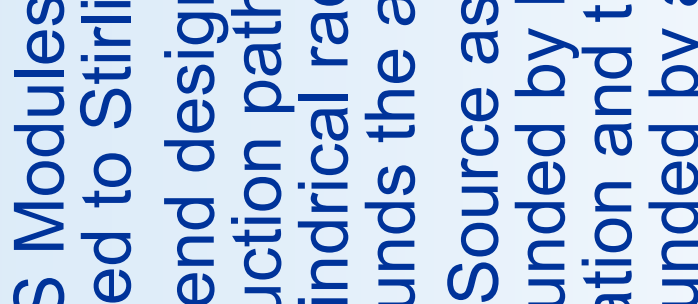

in 0

$\frac{0}{\omega}$

은든 응

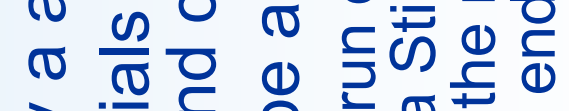

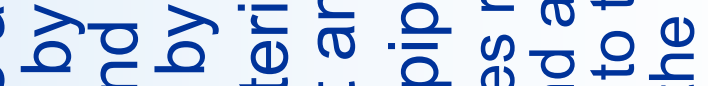

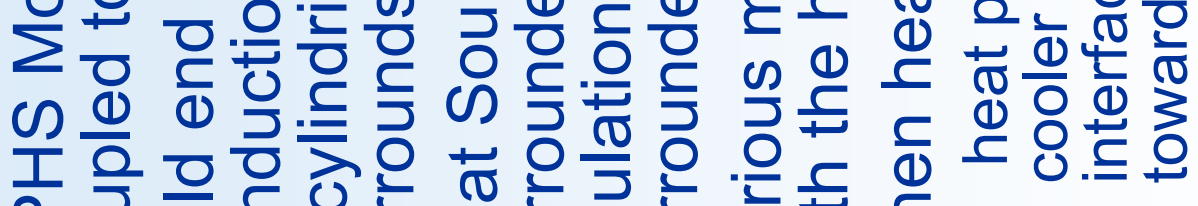

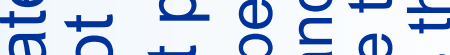

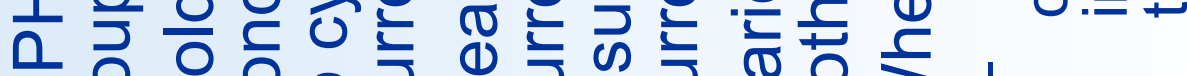

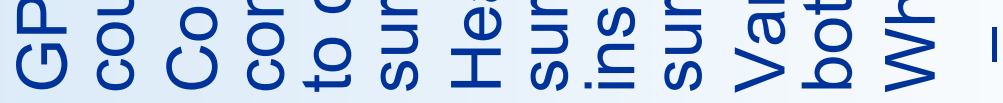

$\frac{0}{\frac{0}{0}}$ 


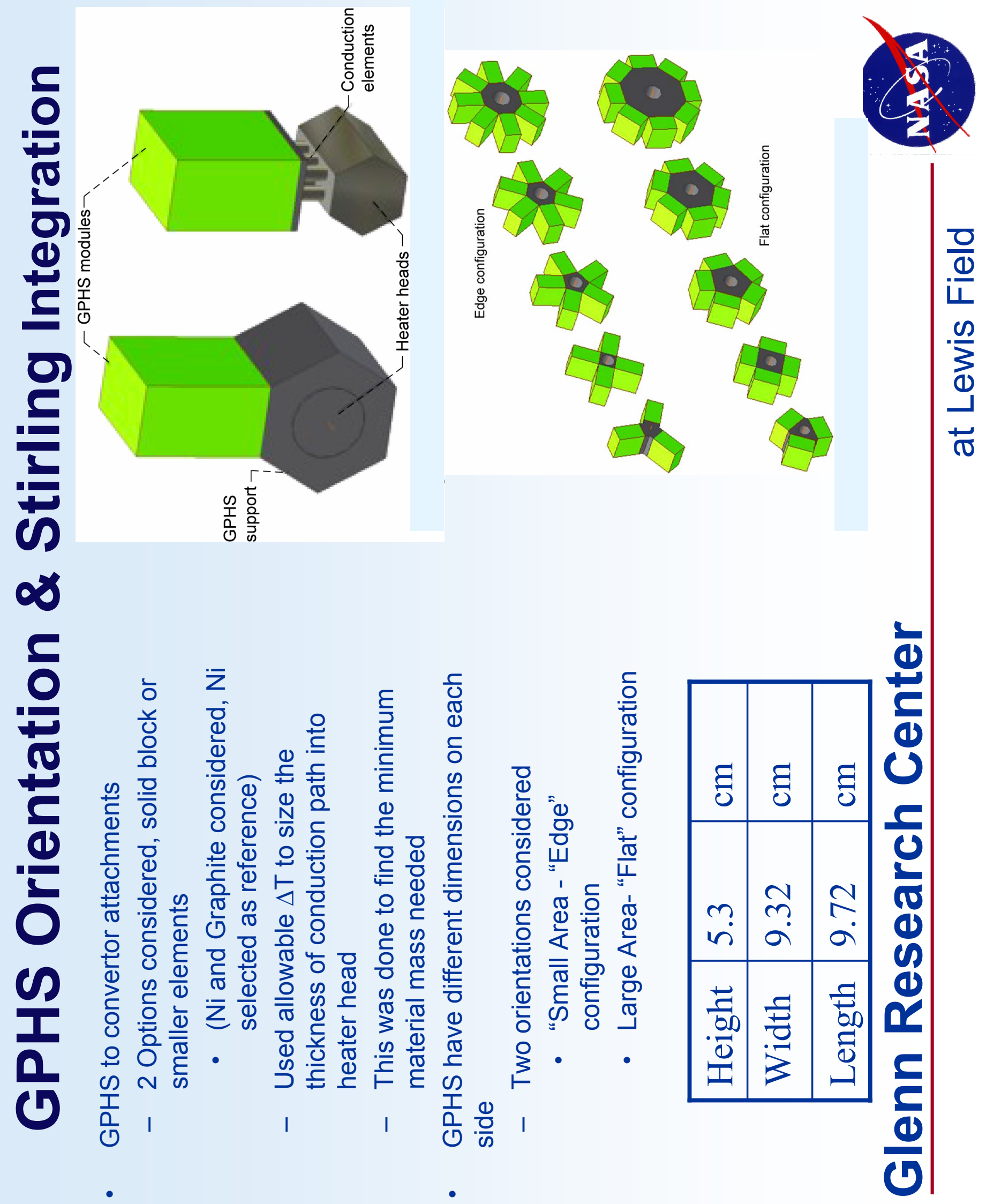



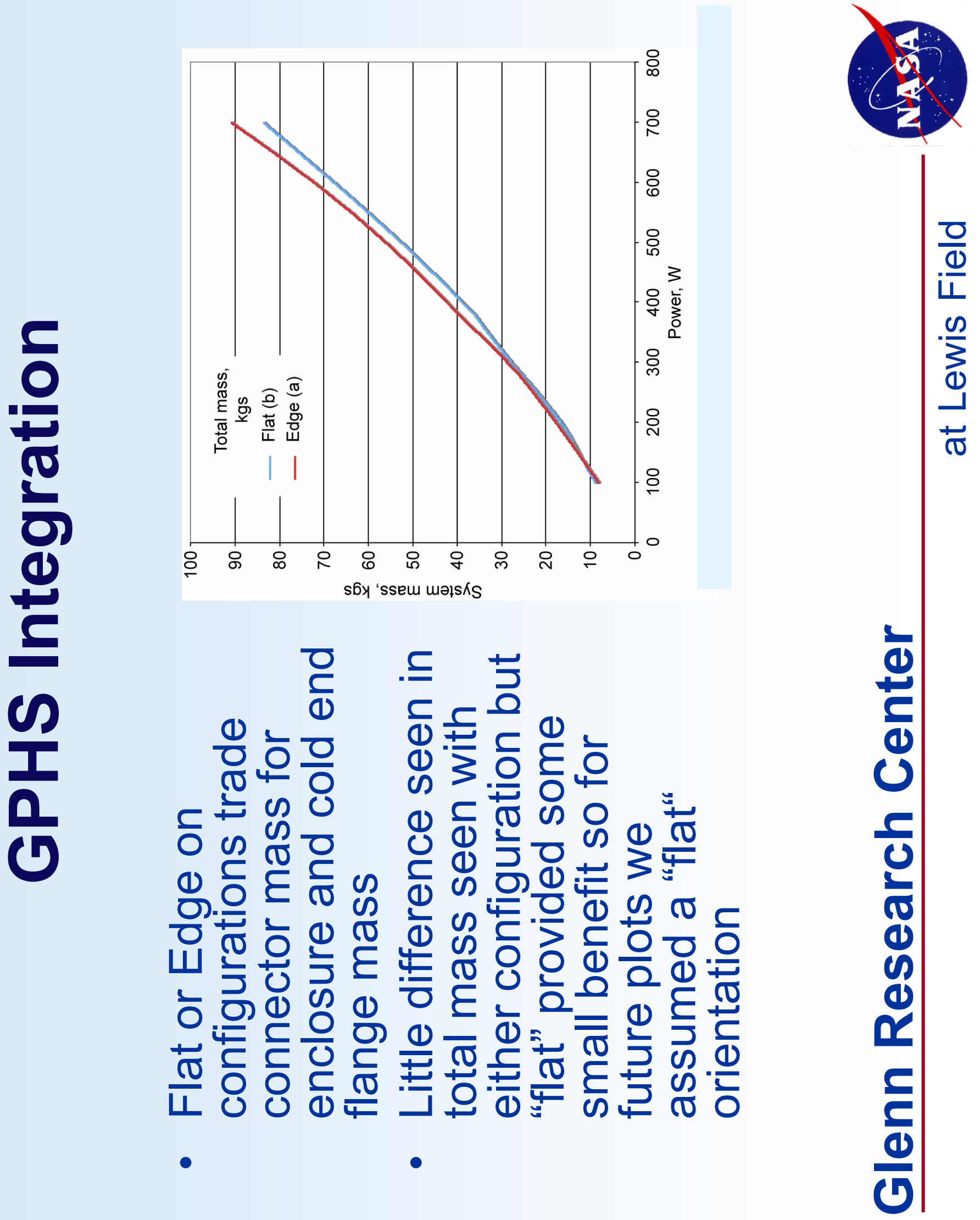


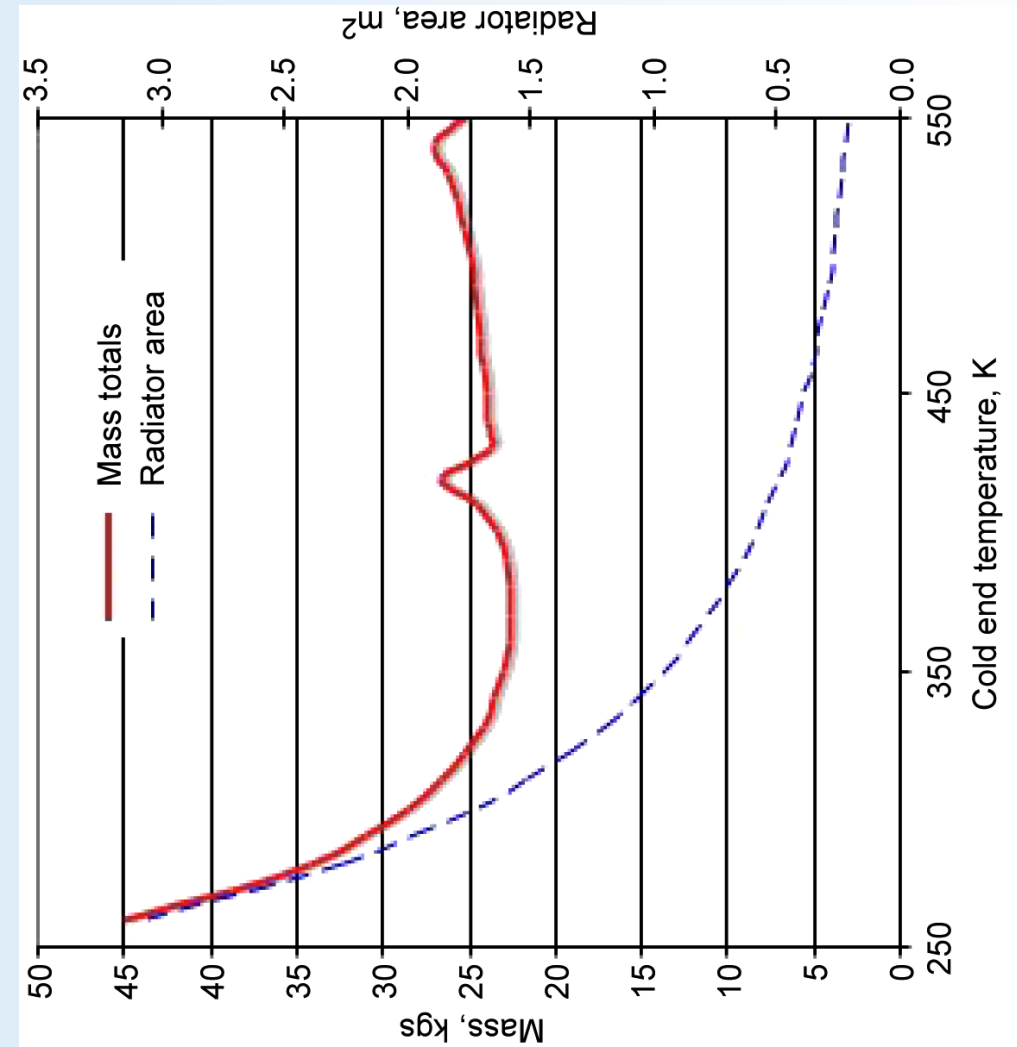

$\frac{0}{0}$
$\frac{1}{4}$
$\frac{0}{3}$
$\frac{1}{\sigma}$
$\frac{\pi}{\sigma}$

$\frac{10}{4}$

E s6y 'ssew
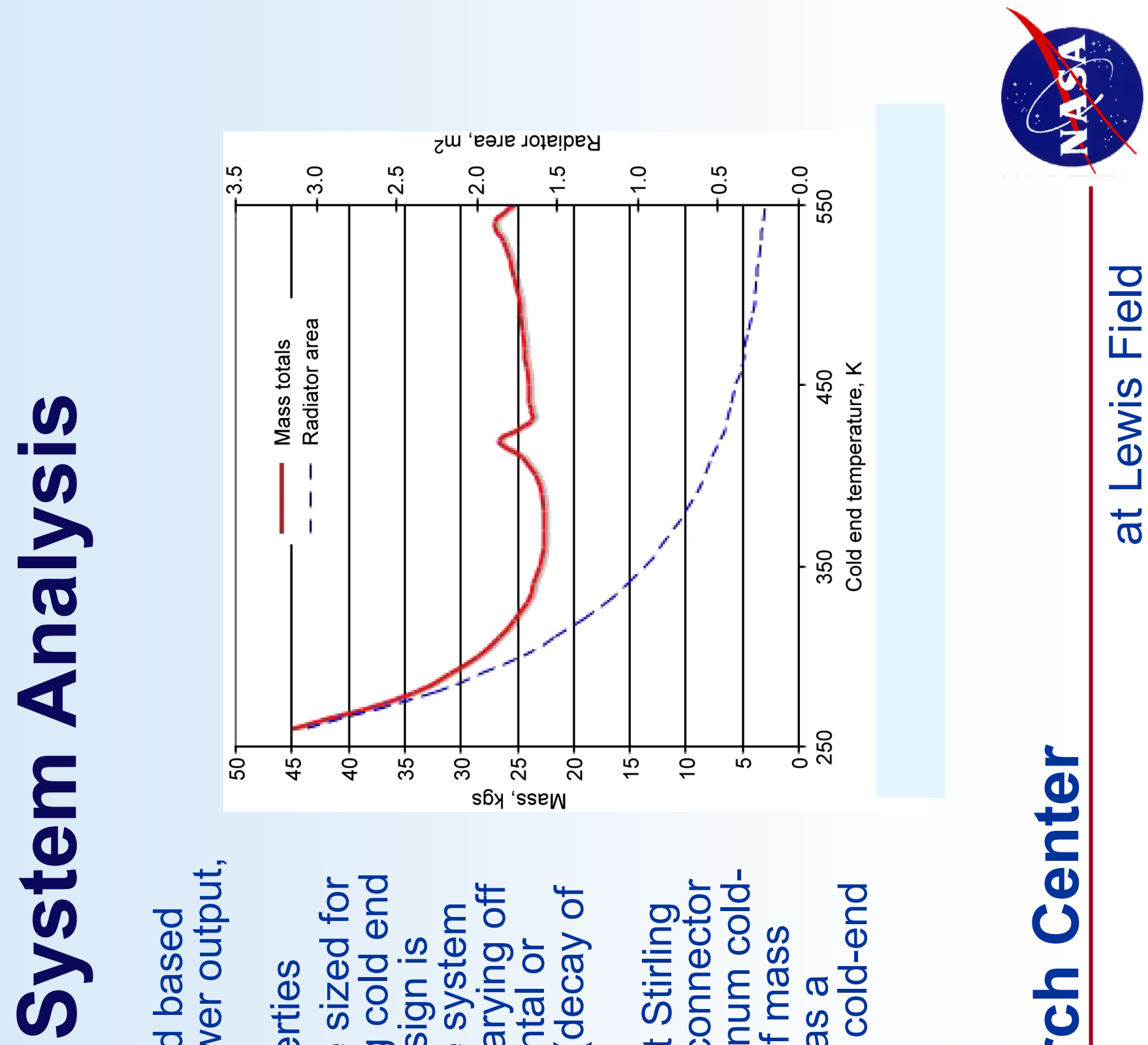

엉

능ำ ह

흄ำ

ஸे

(ช)

(1)

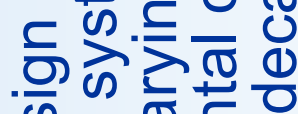

○

(⿺⿻一⿰冫⿰亅⿱丿丶丶

ल $0 . \overline{0}$

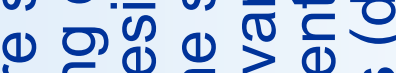

어응ㅇㅇㅇ

రㅇㅇ응

尚: 등

$\mathscr{c}$

\#U.

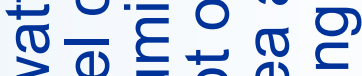

3 또그응

$\frac{1}{\sigma}$

드류

w d

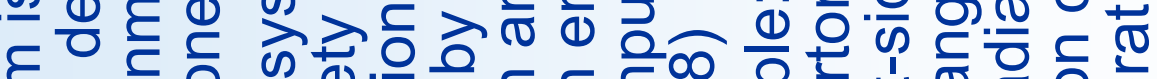

터

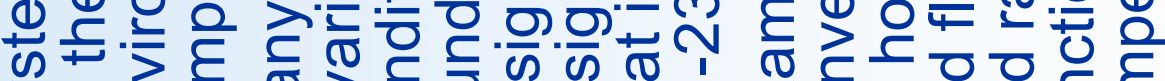

ふ

(4) 
Syग이 SHdO
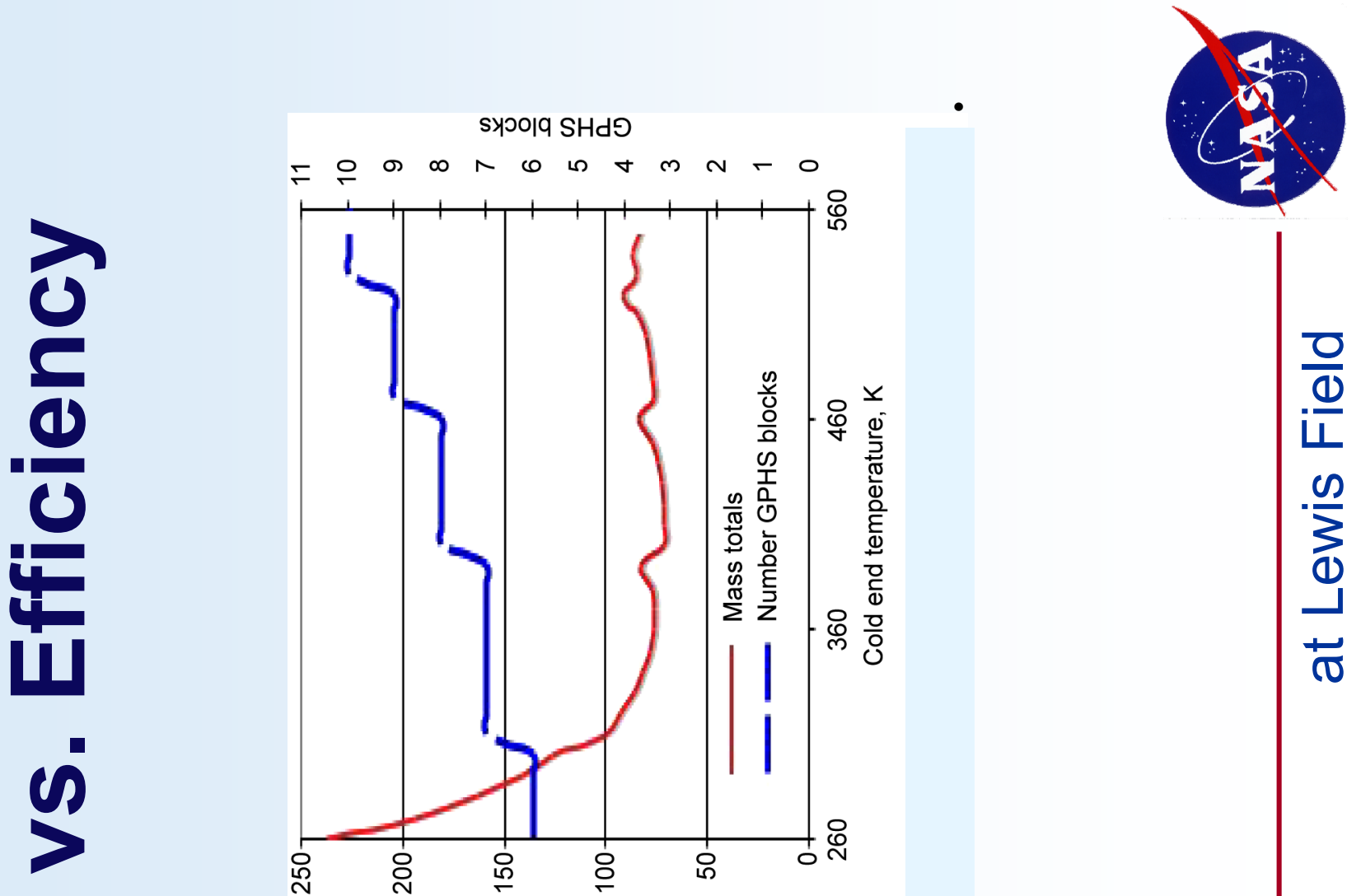

() s6y 'ssew

$\frac{7}{\underline{0}}$

$\sum_{0}^{\infty}$

$+\frac{}{\sigma}$

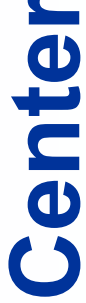

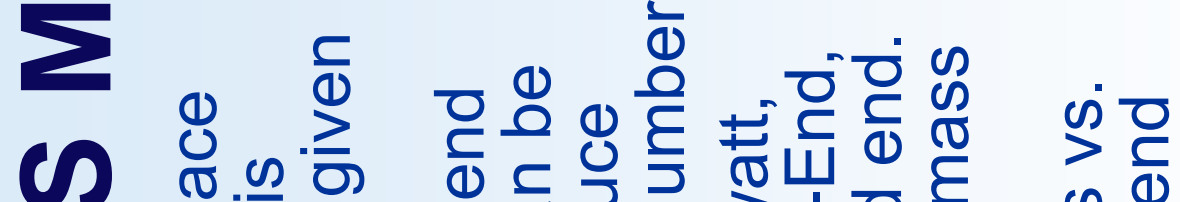
ণে.

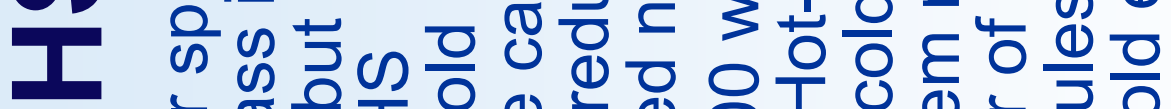

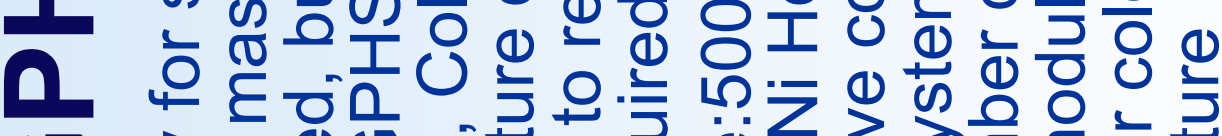

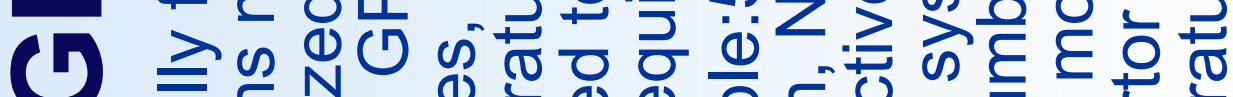
ত্ঠে

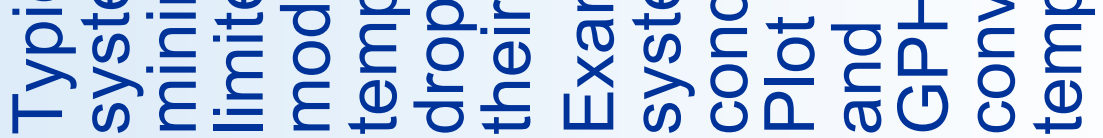




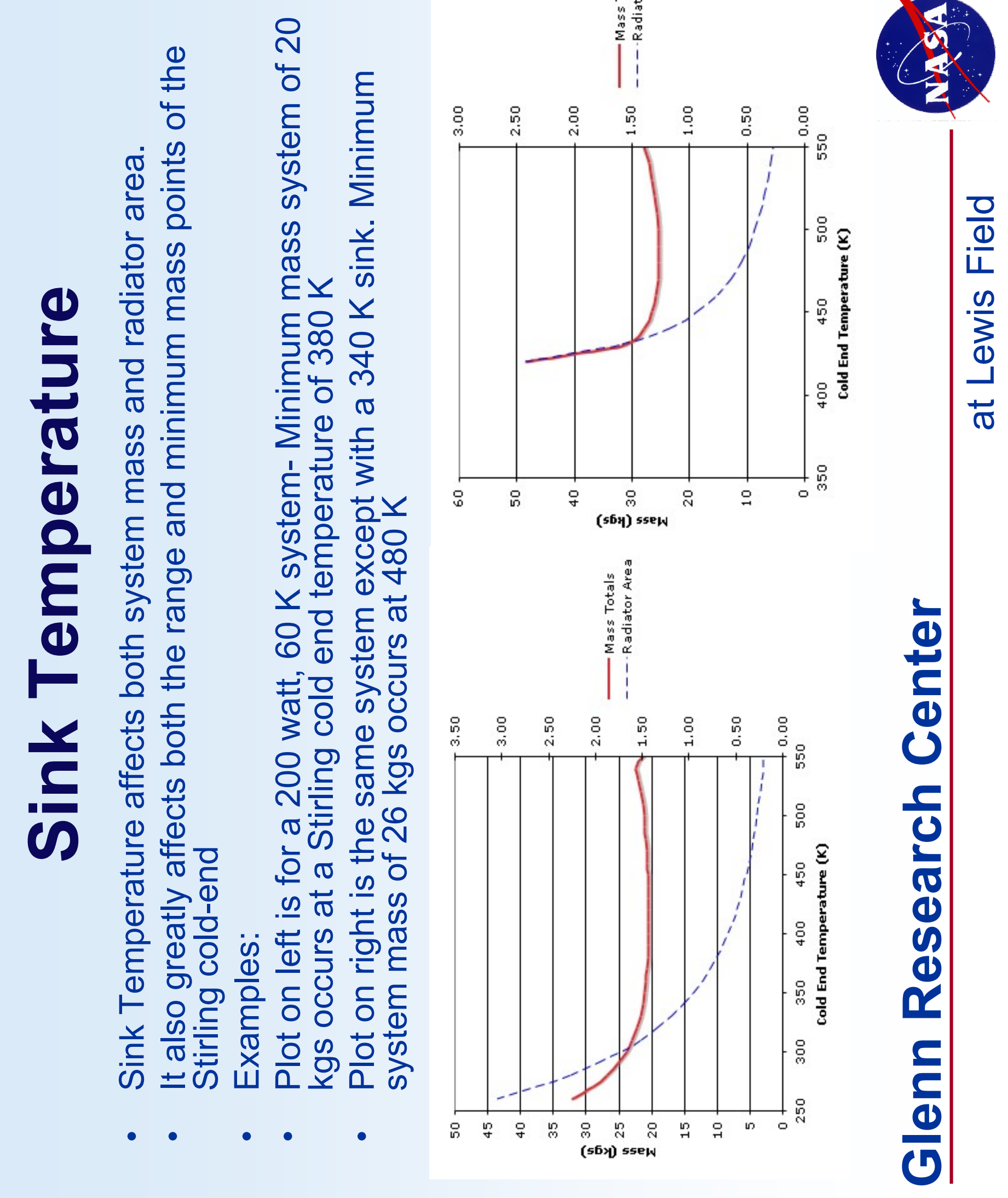



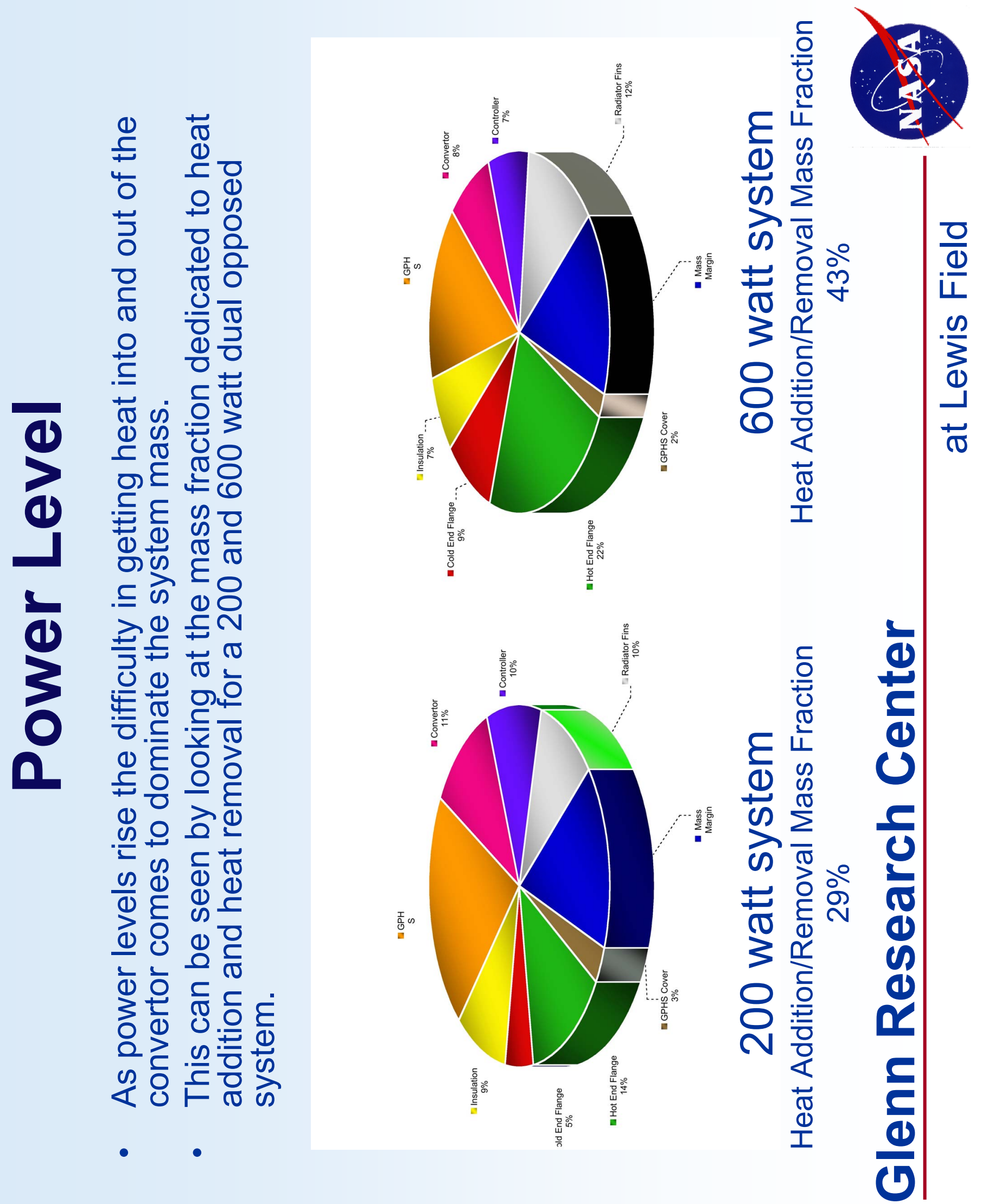


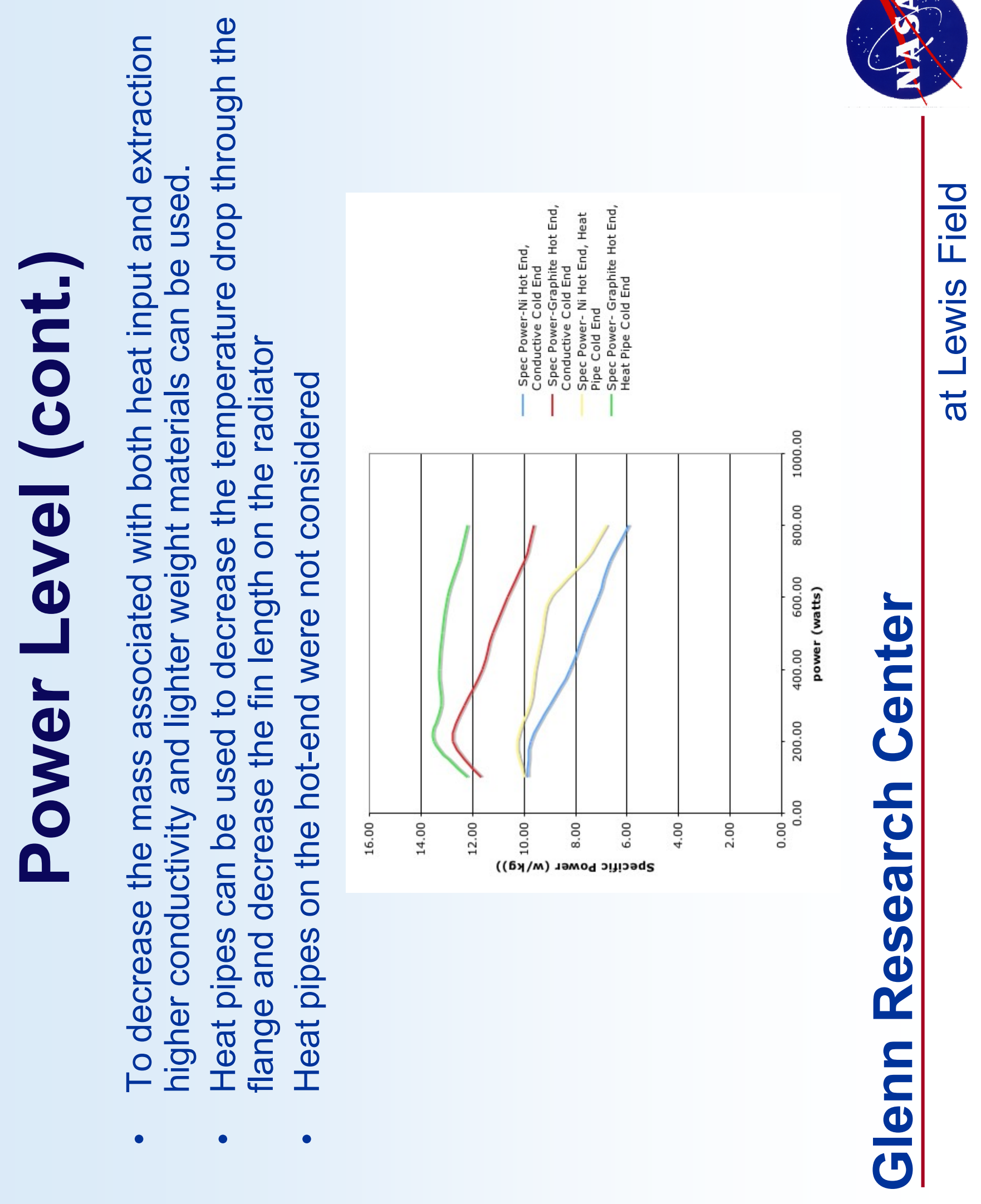




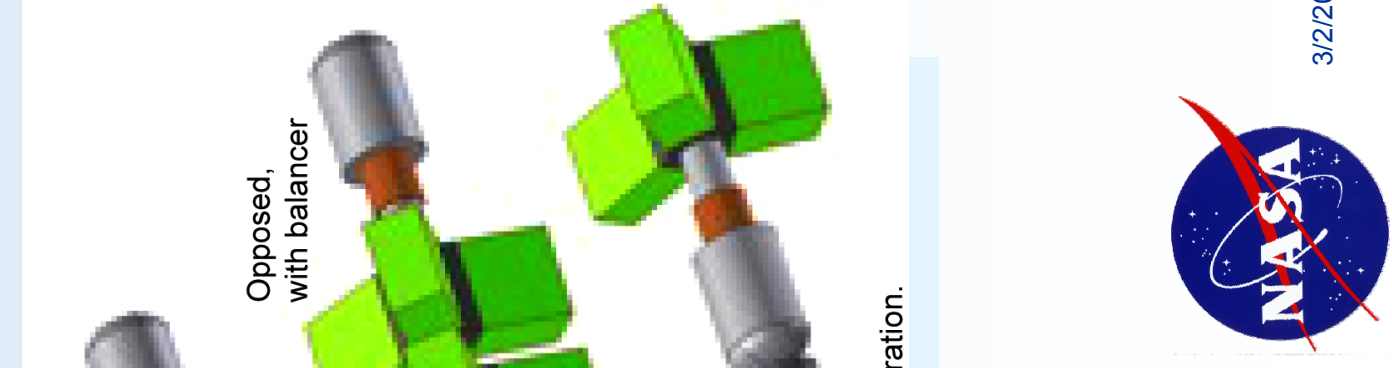

a

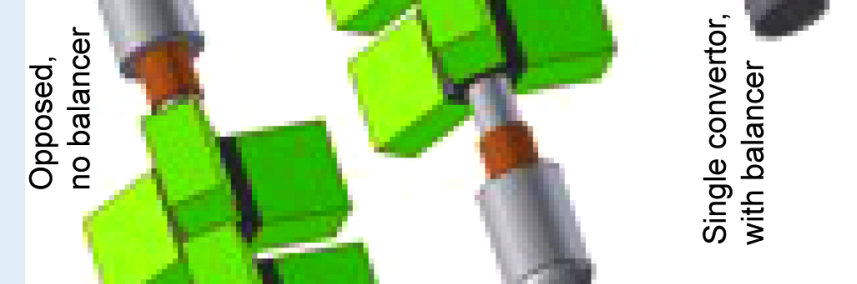

을

$\frac{0}{0}$
$\frac{1}{4}$
$\frac{\pi}{2}$
$\frac{1}{\pi}$

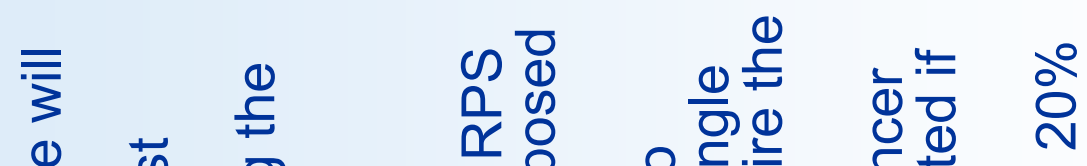

(b)

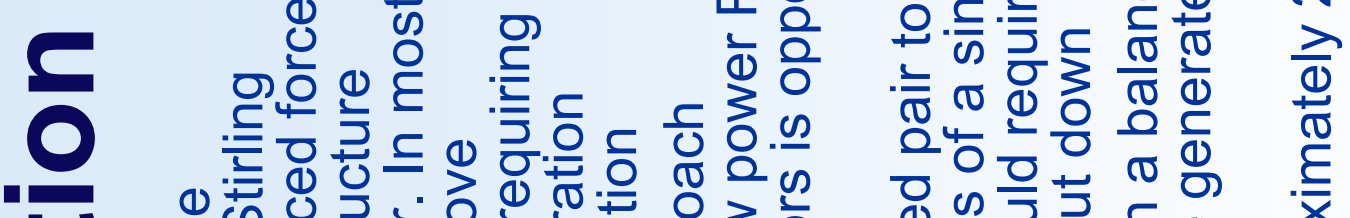

10 1.

90 元过

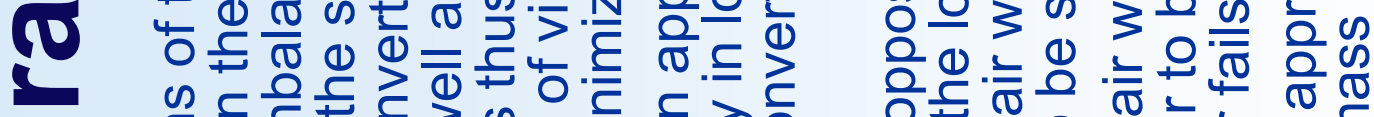

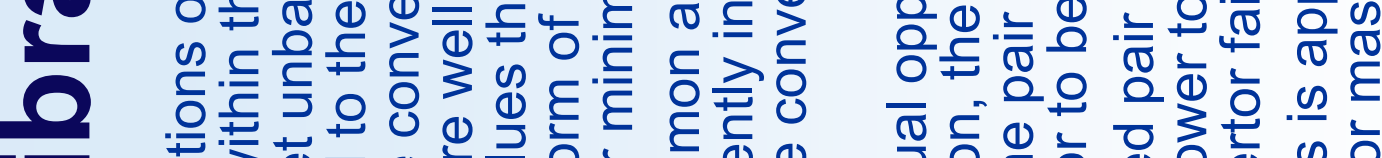

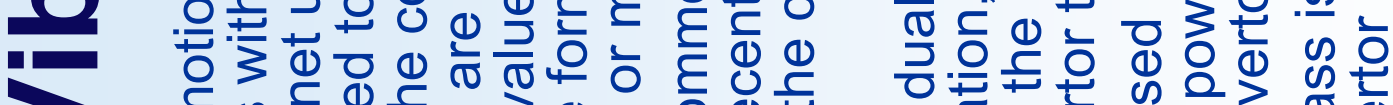
ह

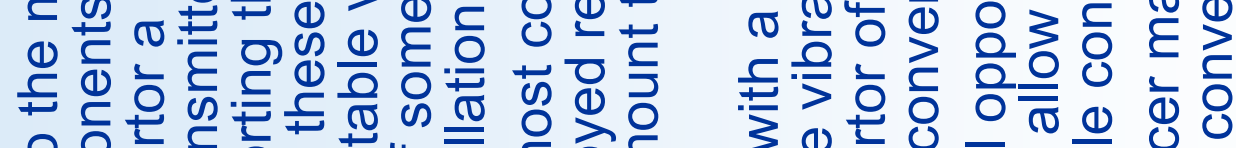

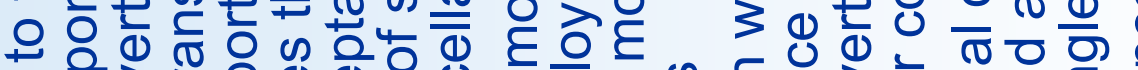
(1) 틀 은

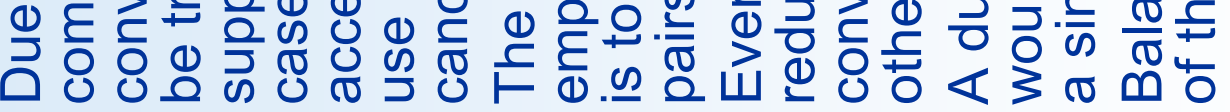




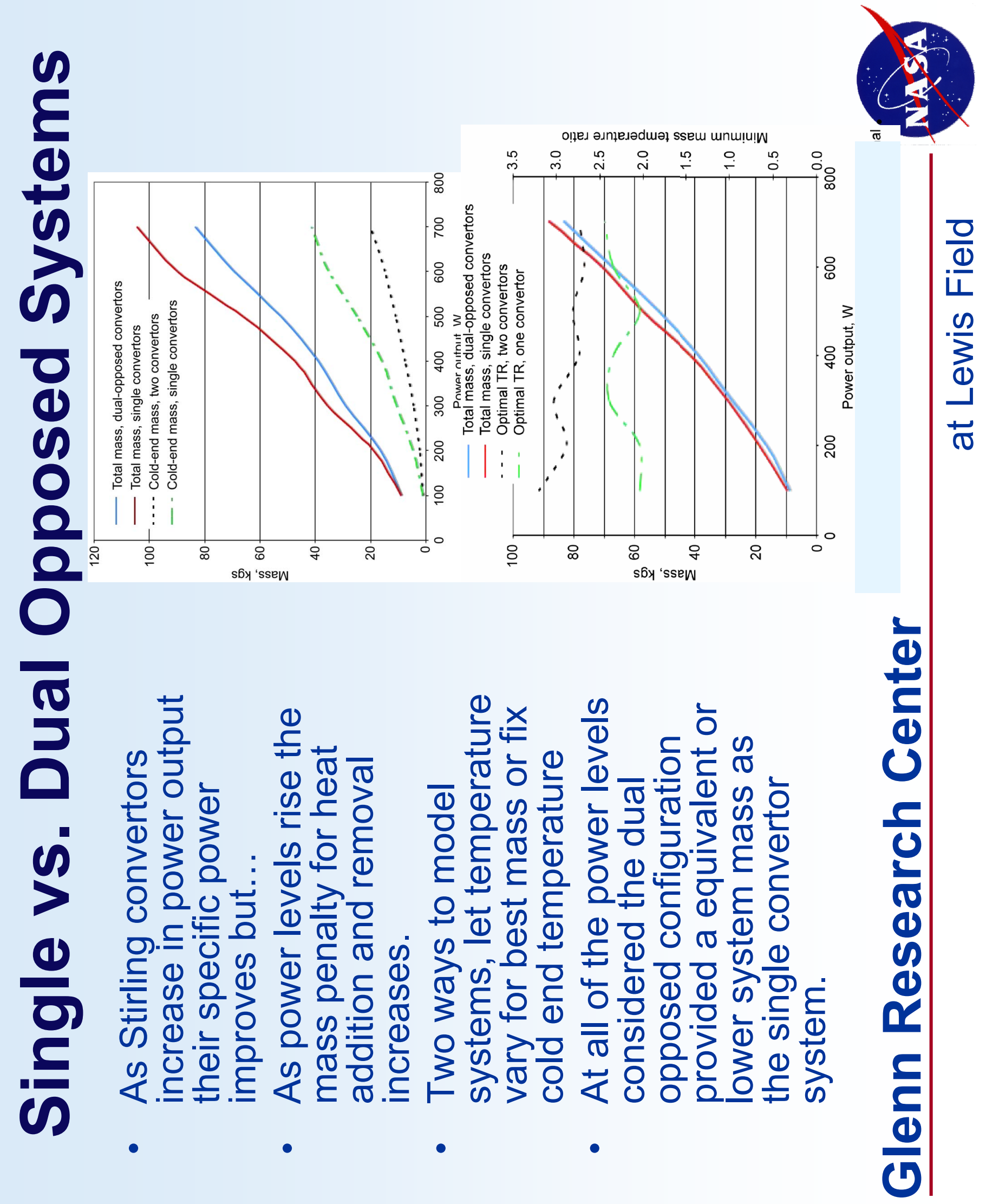




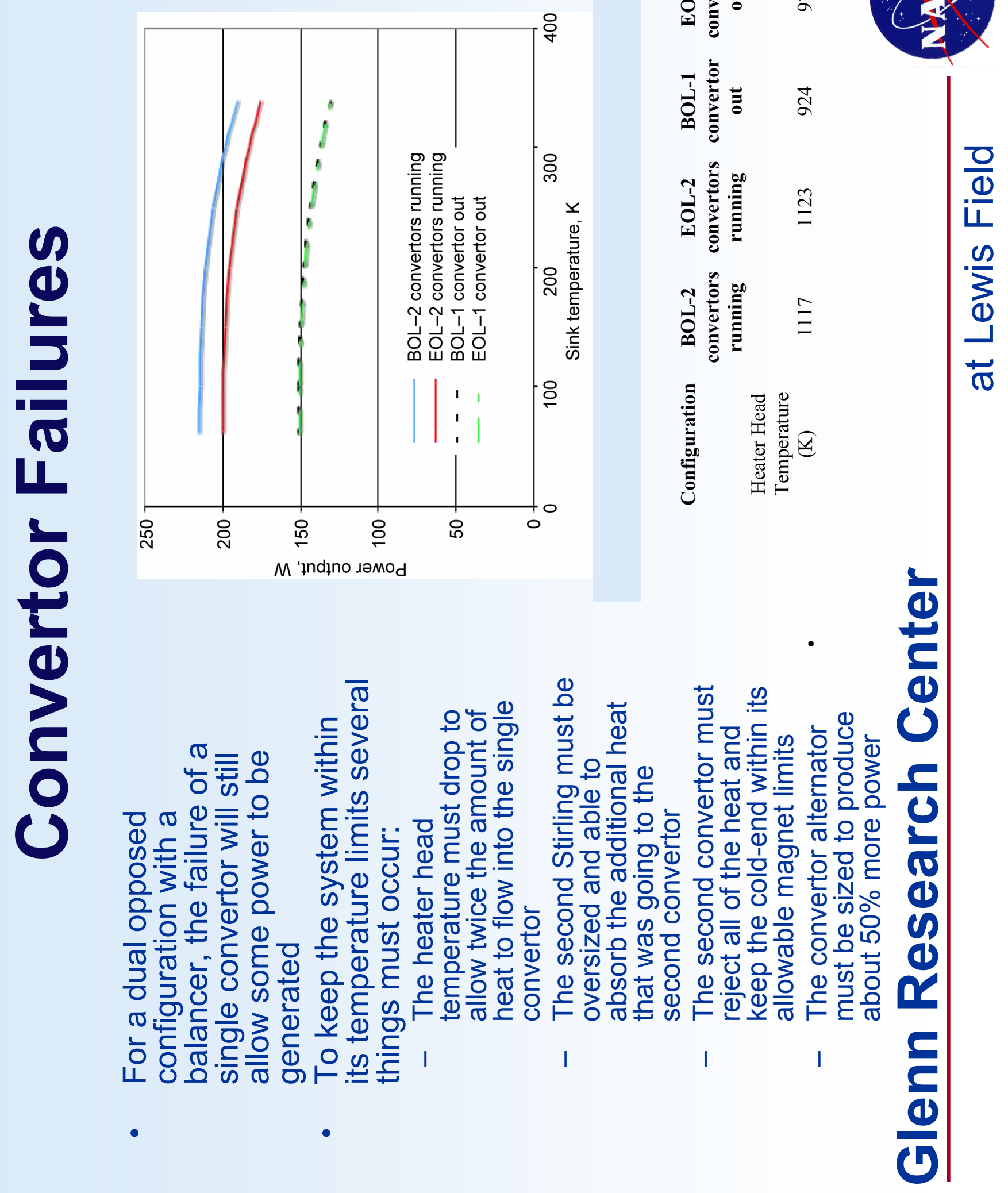




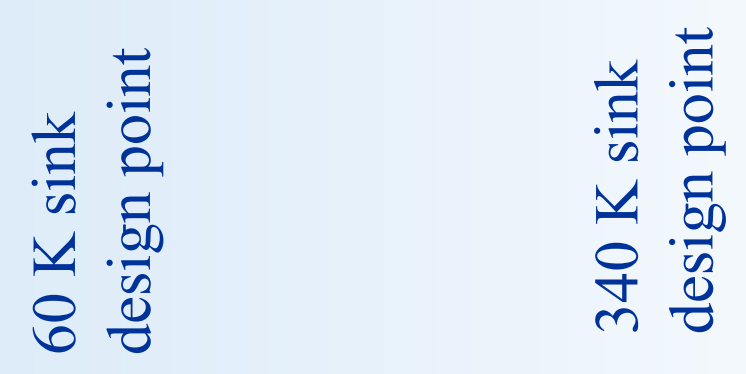

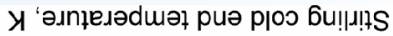

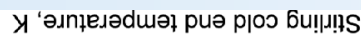
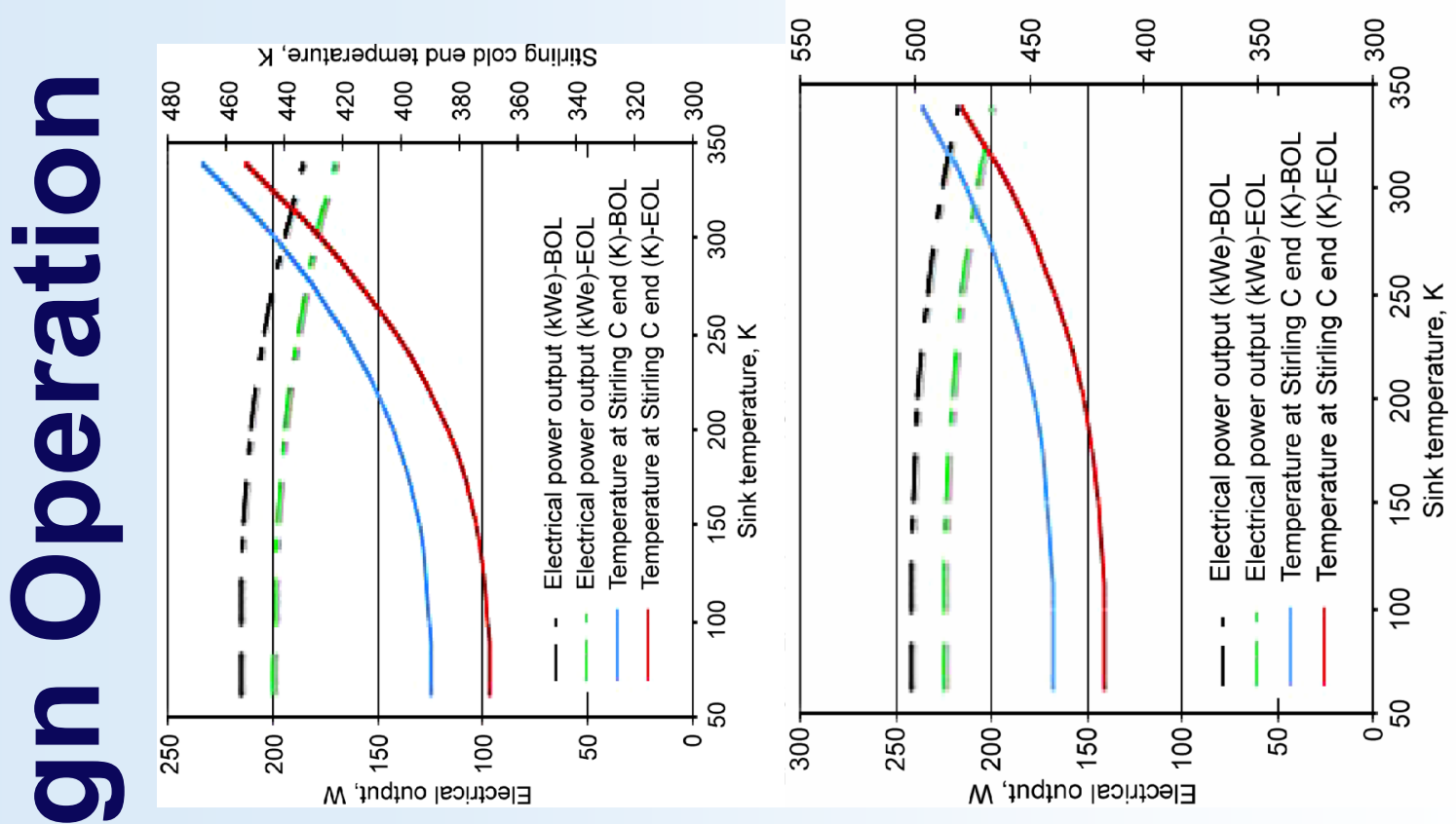

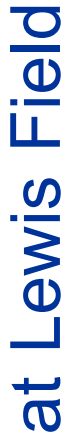

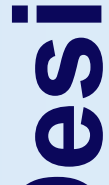

苦

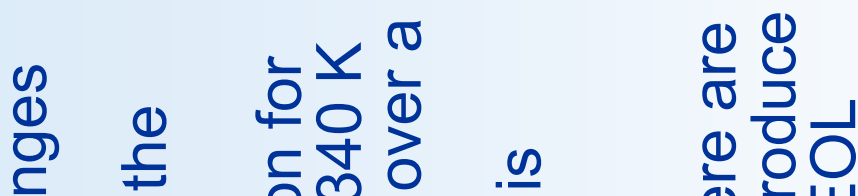

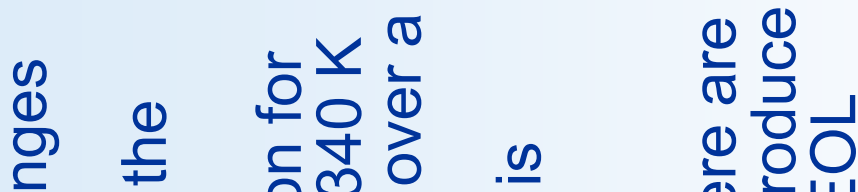

ป气 는

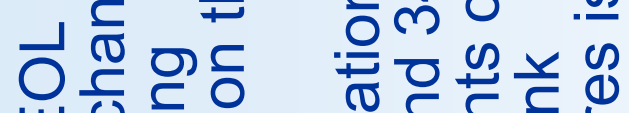

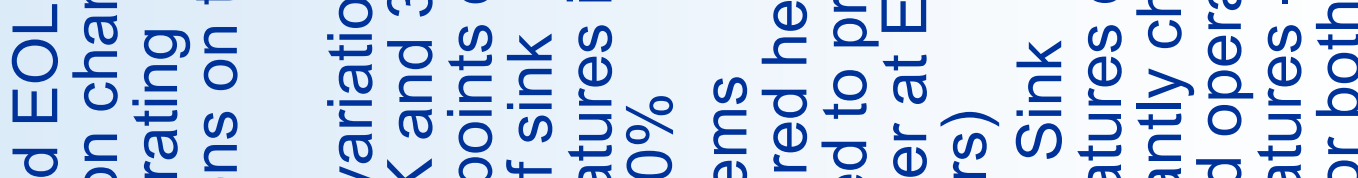

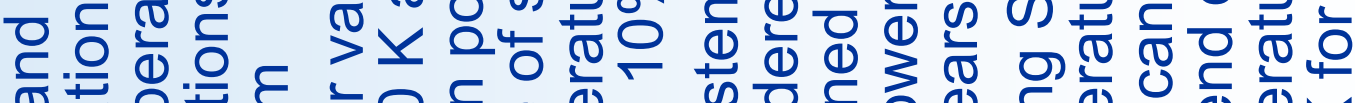

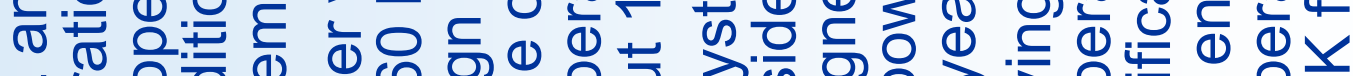

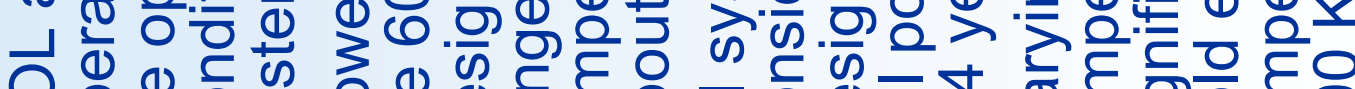
응워

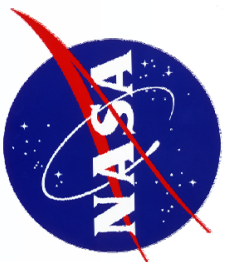




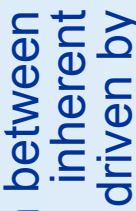

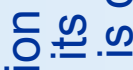

$\stackrel{0}{\frac{5}{2}} \frac{2}{\omega}$

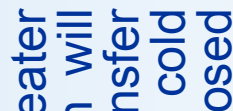

든 는

केषั

구의

넉으 $\frac{\varepsilon}{\mathrm{d}}$

$\therefore$ ×

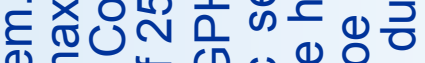

O

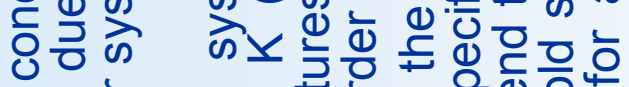

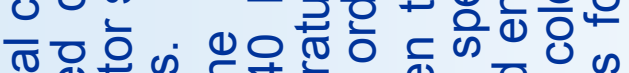

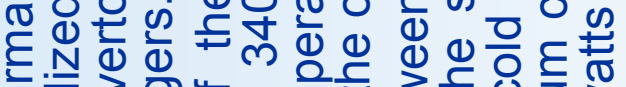

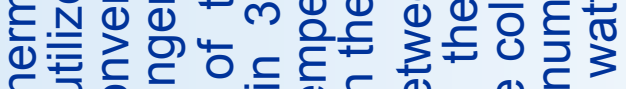

‡开

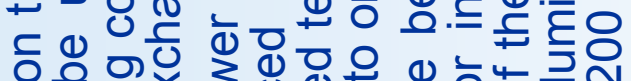

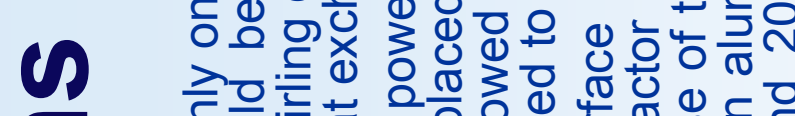

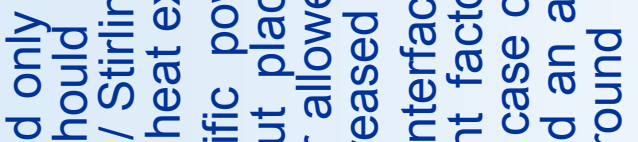

응 $\frac{1}{\omega}$

めल

ఠֻ

(1)

F舟的

उ $\frac{0}{0} \cdot \frac{1}{0}$

कृष

$\frac{0}{10}$

ن

त

贾溇

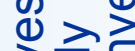

..

녿돌

오응

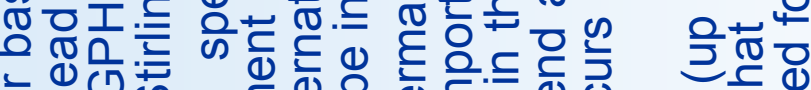
屯㐫凹

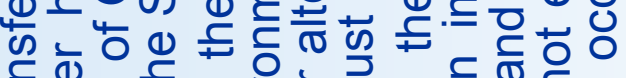

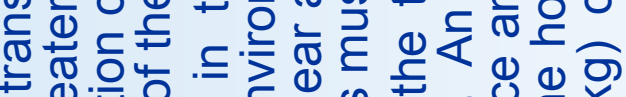

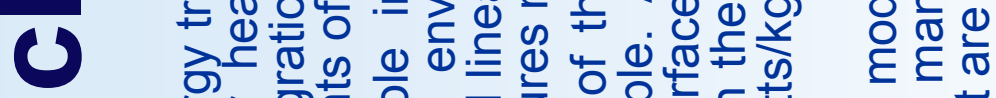

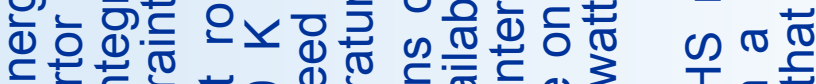

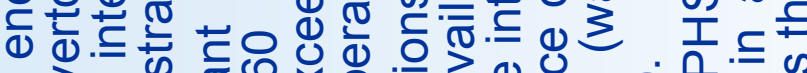
근

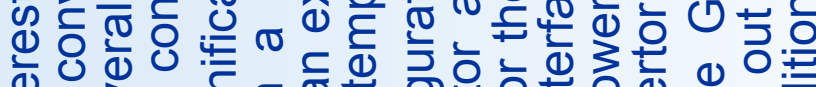
ब

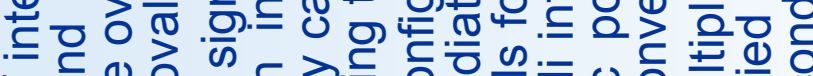
पర兀

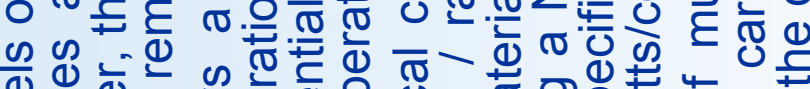

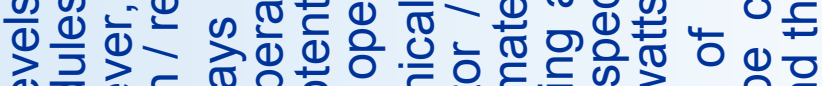

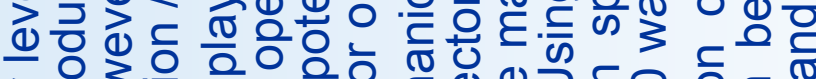

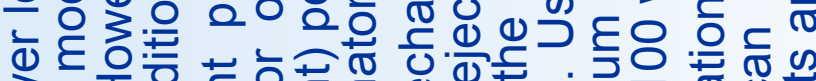

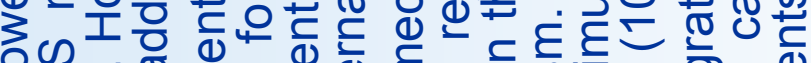

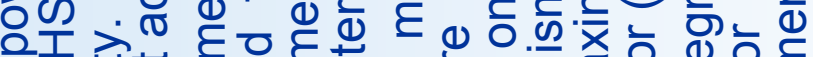

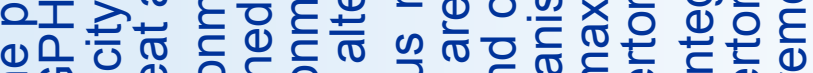

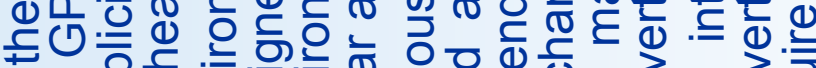

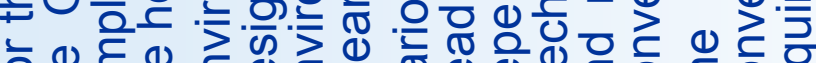

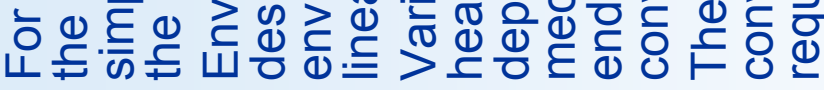

